\title{
Família, conservadorismo e políticas sociais no Brasil: questões para reflexão
}

\author{
Family, conservatism and social policies in Brazil: \\ questions for reflection
}

\author{
Ilka de Lima Souza* \\ Rita de Lourdes de Lima**
}

\begin{abstract}
Resumo - Neste artigo visamos discutir o familismo nas políticas sociais brasileiras na cena contemporânea. A partir de uma revisão bibliográfica, apresentamos, inicialmente, aspectos da formação sócio-histórica brasileira e suas implicações na configuração da família. Para isso, discutimos as principais características de nossa formação: conservadora, patriarcal, paternalista e patrimonialista. Em seguida, analisamos como o familismo, presente no campo das políticas sociais no Brasil, ao mesmo tempo em que, de um lado, se respalda em um discurso de acesso aos direitos, de outro, reforça a sobrecarga das famílias, sobretudo das mulheres, que são responsabilizadas socialmente pelas tarefas domésticas e pelo cuidado com os membros da família. Concluimos ressaltando a necessidade de a sociedade humana avançar na defesa e na busca de valores emancipatórios, por meio da construção de uma nova sociedade. Nesse sentido, precisamos problematizar o familismo nas políticas sociais, desmistificando os limites intrínsecos de uma análise que a desconecta da genericidade humana.
\end{abstract}

Palavras-chave: família; políticas sociais; formação sócio-histórica brasileira; conservadorismo.

\begin{abstract}
In this article we aim to discuss familism in Brazilian social policies in the contemporary scene. From a bibliographic review, we present, initially, aspects of the Brazilian sociohistorical formation and its implications in family configuration. For this, we discuss the main characteristics of our formation: conservative, patriarchal, paternalistic, patrimonialist. We analyze how familism, in the field of social policies in Brazil, at the same time that, on the one hand, it is based on a discourse of access to rights, on the other, it reinforces the overload of families, es-
\end{abstract}

\footnotetext{
* Assistente Social, doutora em Serviço Social pela Universidade Federal do Rio de Janeiro (UFRJ). Docente do Departamento de Serviço Social da UFRN. E-mail: Ika_limasouza@yahoo.com.br. ORCID: https://orcid.org/00000002-8917-6795.

** Assistente Social, doutora em Serviço Social Universidade Federal de Pernambuco (UFPE). Docente do Programa de Pós-graduação em Serviço Social da UFRN. E-mail: rita.pires2@gmail.com. ORCID: https://orcid.org/00000002-7920-115X
} 
pecially of women, who are socially responsible for household chores and caring for family members. We conclude by highlighting the need of human society to advance in the defense and the search for emancipatory values, by means of the construction of a new society. In this sense, we need to problematize the familism in social policies, demystifying the intrinsic limits of an analysis that disconnects it from human genericity.

Keywords: family; social politics; brazilian sociohistoric formation; conservatism.

\section{Introdução}

Há muitas nuances e inúmeras possibilidades de perspectivas ao se discutir família e políticas sociais no Brasil. Diante disso, neste artigo pretendemos apresentar algumas considerações sobre o familismo presente nas políticas sociais brasileiras na contemporaneidade. Para isso, optamos por, inicialmente, considerarmos a formação sócio-histórica brasileira, que imprime peculiaridades à nossa cultura e, consequentemente, traz fortes rebatimentos na família e na forma como se estruturam o Estado e as políticas sociais no país. Discutimos e apresentamos alguns traços gerais de nossa formação sócio-histórica, autoritária, conservadora, paternalista e patriarcal.

Desse modo, no campo das políticas sociais, as marcas dessa formação se estruturam por meio da proposta familista, que estabelece a família como principal sujeito de suas ações. Defendemos ao longo do texto que, ainda que respaldada em um discurso de assegurar direitos às famílias e seus membros, a proposta pautada no familismo tende a sobrecarregá-las, sobretudo as mulheres. Isso acontece uma vez que são estas, particularmente as da classe trabalhadora mais empobrecida, que assumem as tarefas domésticas diárias e os cuidados com crianças, idosos, doentes etc.

Demarcamos, portanto, que na relação entre Estado e família no Brasil a chamada parceria entre essas duas esferas da vida social se materializa em um cenário cuja intensificação das desigualdades e da precarização de direitos sociais, bem como das condições de vida, afeta sobremaneira as famílias da classe trabalhadora. Essas não contam com políticas sociais públicas que efetivamente respondam às suas reais necessidadades. Observamos, na verdade, um Estado sintonizado com as diretrizes do capital, que atua mais no sentido de fortalecer a "solidariedade informal", os apoios provenientes das redes primárias ou informais, e não no impulsionamento de políticas alicerçadas no conhecimento, no respeito e na análise crítica e ampliada da realidade que perpassa o cotidiano daquelas famílias.

Nesse sentido, concluímos defendendo a pertinência de se (re)discutir o familismo e a organização das políticas sociais públicas, pensando possibilidades que apontem para sua superação, mas, ao mesmo tempo, que defendam a necessidade de superar soluções pontuais que efetivamente não resolvem. Além disso, entendemos, no debate que envolve a referida 


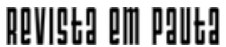

\} FAMÍLIA, CONSERVADORISMO E POLÍTICAS SOCIAIS NO BRASIL - SOUZA, I. L.; LIMA, R. L. \}

DOI: $10.12957 /$ REP.2019.45219

temática, a imprescindibilidade de apreendermos e analisarmos a instituição social família, evidenciando-a em sua diversidade e analisando as contradições inerentes ao universo familiar.

\section{A família na formação sócio-histórica brasileira}

O Brasil teve seu processo de colonização com base na religião católica e, consequentemente, seus valores foram alicerçados no imaginário judaico-cristão ocidental. Neste sentido, tal imaginário, aliado a determinadas peculiaridades da formação socioeconômica brasileira, fizeram surgir e tornar-se hegemônico o modelo familiar patriarcal, a partir do ciclo da cana-de-açúcar no Nordeste.

O modelo de família patriarcal dominante no Nordeste brasileiro ${ }^{1}$ enfatizava a autoridade máxima do pai de família sobre todos os outros membros familiares, num poder incontestável ${ }^{2}$. Tal poder se estendia a parentes e agregados, pois as famílias eram, na verdade, extensos clãs que serviam para legitimar e garantir o poder de seu chefe ${ }^{3}$. Os casamentos, via de regra, visavam unir famílias importantes e contavam com controle de sexualidade e regulação da procriação com vistas à questão da herança e sucessão ${ }^{4}$.

A estrutura econômica de base agrária, latifundiária e escravocrata do Brasil colonial - associada a outras condições, tais como descentralização administrativa local, excessiva concentração fundiária e acentuada dispersão populacional - determinou a instalação de uma sociedade paternalista, na qual as relações de natureza pessoal se tornaram deveras importantes. (OSTERNE, 2001, p. 60).

A dimensão gigantesca, a subserviência cultural e econômica aos países centrais, enquanto país periférico no capitalismo mundial, acompanharão a história brasileira e estabelecerão algumas características próprias em nossa cultura: autoritarismo, verticalismo, tutela e favor.

Ao dizer que a sociedade brasileira é autoritária estou pensando em certos traços gerais das relações sociais que se repetem em todas as esferas da vida social (da família ao Estado, passando pelas relações de trabalho, pela escola, pela cultura). Vivemos numa sociedade verticalizada e hie-

\footnotetext{
${ }_{1}$ A família nuclear burguesa como a conhecemos hoje só surge no século XVII. Para uma discussão acerca do surgimento da família, sugerimos o clássico de Engels (s.d.).

${ }^{2} \mathrm{O}$ modelo familiar brasileiro deste período compreendia pai, mãe, filhos e agregados em geral (afilhados, primos, sobrinhos etc., qualquer um que morasse na casa grande sob a autoridade do homem).

${ }^{3}$ Deteremo-nos, especificamente, na formação familiar brasileira; contudo, o surgimento da instituição famíliar patriarcal remete à sociedade romana antiga, na qual já cabia ao homem poder de vida e morte sobre todos os membros familiares, conforme atesta o clássico de Engels (s.d.).

${ }^{4}$ Tal organização, entretanto, contrastava com a organização familiar plebeia - que não era cobrada a obedecer as normas burguesas -, na qual predominava mancebia, ligação transitória e poliandria difusa (OSTERNE, 2001).
} 
rarquizada (embora não o percebamos) na qual as relações sociais são sempre realizadas ou sob a forma de cumplicidade (quando os sujeitos sociais se reconhecem como iguais), ou sob a forma do mando e da obediência entre um superior e um inferior (quando os sujeitos são percebidos como diferentes, a diferença não sendo vista como assimetria, mas desigualdade). [...] A forma autoritária da relação é mascarada por aquilo mesmo que a realiza e a conserva: as relações de favor, tutela e clientela. (CHAUí, 1994, p. 27).

Desse modo, as constantes "revoluções pelo alto", os governos autoritários, a apropriação do dinheiro público e o conhecido "jeitinho brasileiro", aliados ao ufanismo de ser um país privilegiado do ponto de vista das belezas naturais ${ }^{5}$, estabelece uma formação com características próprias, que rebatem também no âmbito familiar, tornando-o muito mais autoritário, heterossexista e patriarcal. "A nossa formação é acompanhada por características históricas de nossa cultura, como o autoritarismo, o patrimonialismo, o clientelismo, o racismo, o patriarcalismo, a privatização do público, que se combinam entre si" (CISNE; SANTOS, 2018, p. 99).

Assim, características específicas da nossa sociedade farão do homem não só o chefe da família, mas também o patriarca, o coronel, o dono do poder econômico e político (OSTERNE, 2001). Destarte, apesar das conquistas do movimento feminista ${ }^{6}$ ao longo da história - como sufrágio feminino, direito à educação, inserção no mercado de trabalho, divórcio etc. -, permanece predominantemente o modelo no qual cabe ao homem a última palavra, mesmo em funções tradicionalmente destinadas à coordenação das mulheres, mas que, apesar disso, não lhes confere poder de mando e decisão $^{7}$. Ao mesmo tempo em que a sociedade estabelece a obediência das mulheres aos homens, a elas também se imputam todas as funções de cuidado e nutrição no âmbito familiar.

É do trabalho no seio da família ao que se estende ao trabalho assalariado que, em grande medida, as mulheres vão assegurando de maneira gratuita e/ou mal remunerada a chamada reprodução social antroponômica, que se refere 'ao cuidado com a educação das crianças, cuidado com os idosos e com as pessoas doentes, manutenção material das residências, dos espaços de estudo, de trabalho e vida social'. (CISNE; SANTOS, 2018, p. 61).

\footnotetext{
${ }^{5}$ O texto de Chauí (1994) ressalta a construção ideológica do Brasil, apresentado como "paraíso natural". A esse conjunto de ideias soma-se a cultura patriarcal, que enfatiza a mulher brasileira como "elemento" integrante desse paraíso, "beleza natural", a ser desfrutada pelos homens.

6 "O feminismo, [...] indica historicamente conjuntos variados de teorias e práticas centradas em volta da constituição e da legitimação dos interesses das mulheres. Nesta perspectiva, o feminismo é mais uma questão histórica do que uma questão de definição" (ERGAS, 1991, p. 588).

7 "O papel da Mulher eu acredito que seja cuidar bem do esposo e do filho, procurar ser paciente". "O papel da Mulher é respeitar o marido, não andar com chafurdo no meio da rua [...] Quem manda nessa famia é meu marido. Por exemplo, eu compro as coisas, só que quando ele chegar eu vou e falo, agora [...], se ele não concordar eu vou e devolvo" (OSTERNE, 2001, p. 215-216).
} 


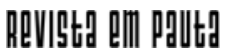

\} FAMÍLIA, CONSERVADORISMO E POLÍTICAS SOCIAIS NO BRASIL - SOUZA, I. L.; LIMA, R. L. \}

DOI: $10.12957 /$ REP.2019.45219

Em uma sociedade marcadamente verticalizada e autoritária, com uma democracia ainda incipiente, a sedução por discursos autoritários, conservadores e de extrema direita se mantém. Em tempos de crise ${ }^{8}$, a burguesia ${ }^{9}$ brasileira, acostumada a saídas pelo alto e a não ter seu poder questionado, opta por respostas autoritárias. Por meio de um discurso ideológico e utilizando os meios de comunicação, apresenta um salvador - bem ao gosto da formação cristã brasileira - que "resolverá" os problemas enfrentados pela burguesia, apresentando a solução como necessária e urgente para o país; portanto, necessária para todos. Nos termos de Marx e Engels (1991, p. 49, p. 74):

Toda classe que aspira a dominação [...] deve conquistar primeiro o poder político, para apresentar seu interesse como interesse geral, [...] a apresentar seus interesses como sendo o interesse comum de todos os membros da sociedade, isto é, para expressar isso mesmo em termos ideais: é obrigada a emprestar as suas ideias a forma de universalidade.

Desse modo, é nesse ranço cultural burguês, patriarcal, racista, autoritário e conservador que se gesta a candidatura de Jair Messias Bolsonaro, eleito presidente da república em 2018. Com ele, reacende-se a defesa da família como instituição responsável pela ordem, estabilidade e moralidade da sociedade. No caso das políticas sociais no Brasil, a partir dos anos $1990^{10}$, já se enfatizava a família como sujeito principal de suas ações e propostas, respaldadas em um discurso de acesso a direitos e necessidade de "empoderamento"11 feminino. Contudo, no Brasil, país historicamente marcado por uma cultura autoritária, enorme desigualdade social e ausência de políticas públicas efetivas, precisamos analisar com mais cuidado as propostas de políticas sociais que enfatizam a centralidade da família. É disso que trataremos a seguir.

\section{Conservadorismo e familismo nas políticas sociais na contemporaneidade}

Na relação que envolve família e Estado no Brasil, configura-se um Estado que ora sinaliza uma responsabilidade em assegurar a proteção social às famílias e aos indivíduos que as constituem - por meio das políticas sociais -, ora reforça a concepção de família como responsável primeira pelo bem-estar de seus membros. O desenho de políticas sociais com cen-

\footnotetext{
${ }^{8}$ Acerca da crise mundial do capital ver, especialmente, Mészáros (2011).

${ }^{9}$ Sobre a estruturação da sociedade capitalista e a luta de classes, conferir Marx e Engels (s. d.).

${ }^{10}$ A construção das políticas sociais com base no familismo remete à Constituição Federal de 1988, entretanto, será a partir dos anos 1990, com a promulgação das leis que regulamentam a Constituição (Estatuto da Criança e Adolescente, Suas, Estatuto do Idoso etc.) que se estabelece, com mais ênfase, o familismo e as discussões sobre empoderamento.

11 Para uma crítica à noção de empoderamento, ver Siqueira (2011).
} 


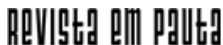

\} FAMÍLIA, CONSERVADORISMO E POLÍTICAS SOCIAIS NO BRASIL - SOUZA, I. L.; LIMA, R. L. \}

DOI: $10.12957 /$ REP.2019.45219

tralidade na família tem demonstrado o sentido dessa relação, na qual as famílias permanecem sendo chamadas a serem "parceiras" do Estado, no sentido de assumirem a proteção social e o bem-estar dos indivíduos que as constituem, bem como no de contribuir, indiretamente, com a garantia de projetos, programas, serviços e benefícios que satisfaçam necessidades básicas. ${ }^{12}$

Em face do exposto, evidenciamos a perspectiva familista que pauta as políticas sociais no país, na qual se tem um Estado que designa para as famílias um máximo de obrigações referentes ao bem-estar de seus membros (ESPING-ANDERSEN, 2011). No âmbito dessas políticas, corporifica-se, conforme observam Gelinski e Moser (2015, p. 131), "o claro chamamento para que as famílias assumam parcela de responsabilidade na proteção social". A isso De Martino (2015) denomina "neofamilismo", em referência a essa orientação familista, na qual se deslocam para as famílias responsabilidades anteriormente assumidas pelo Estado.

Tal modelo ancora-se no discurso (ideológico) recorrente de apelo ao solidarismo e ao voluntarismo do mercado, da família e da sua rede de sociabilidade, que enquanto parceiros contribuem para a 'redução' do papel protetivo do Estado na garantia dos direitos sociais. E à medida que delega à família em primeira instância a proteção de todos os seus membros. (CASTILHO; CARLOTO, 2010, p. 6).

Nessa perspectiva, em que supostamente as famílias são o foco da proteção social, ocupando lugar de destaque em um conjunto de leis, programas e projetos sociais, não necessariamente estão centralizadas a proteção, os serviços ou programas sociais nas famílias, mas em indivíduos que integram essa esfera da vida social, os quais vivenciam situações específicas. São, por exemplo, a criança, o adolescente, a pessoa idosa, a mulher. Percebemos uma limitação, ou mesmo omissão, do Estado quando a atenção às famílias é tratada de forma fragmentada/individualizada, no sentido de dificultar uma leitura ampla em torno das famílias, considerando todos os processos relacionais, a forma como se organizam, as demandas e necessidades sociais que as envolvem.

Compreendemos a necessidade de serem considerados não determinados membros das famílias como sujeitos de direitos, mas as famílias em sua totalidade e, ainda, em sua diversidade, tendo em vista que a tradicional família nuclear - constituída de um casal heterossexual com filhos claramente não está sozinha, nem deve ser idealizada, enquanto configuração familiar, como padrão normativo. Na realidade, famílias com variadas configurações podem buscar o acesso a programas, projetos, serviços,

\footnotetext{
${ }_{12}$ Mioto (2004) ressalta o caráter paradoxal na inter-relação Estado-família evidenciada por estudiosos da temática, os quais analisam que, apesar do reconhecimento da centralidade da família na vida social, existe uma prática e uma negação sistemática desse reconhecimento, havendo uma penalização da família por parte de instituições que deveriam promovê-la.
} 


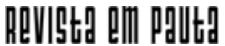

\} FAMÍLIA, CONSERVADORISMO E POLÍTICAS SOCIAIS NO BRASIL - SOUZA, I. L.; LIMA, R. L. \}

DOI: $10.12957 /$ REP.2019.45219

benefícios e ações efetivadas no âmbito das políticas sociais estatais. Além da família nuclear, se faz referência às famílias monoparentais; reconstituídas; homoafetivas, dentre outras configurações, cujos membros estejam ou não ligados por laços consanguíneos, uma vez que as relações de confiança, de amizade e de afeto também se mostram dimensões fundamentais para a conformação de uma família ou sentimento de fazer parte de uma.

Contudo, apesar disso, "se a diversidade familiar foi aceita pela academia e pelos especialistas, não parece haver hegemonizado as apresentações predominantes nas instituições e agentes do Estado" (DE MARTINO, 2015, p. 101). O que ainda observamos no cotidiano dos agentes institucionais e no próprio discurso governamental é uma idealização da família com base em determinado "padrão" ou "modelo", exprimindo uma sintonia com pensamentos conservadores, cujos discursos e ações em torno deste são retomados com intensidade no tempo presente.

A título de exemplo, ressaltamos as recentes iniciativas impulsionadas pela bancada religiosa do Congresso Nacional: o projeto de lei que propõe regras jurídicas para definir quais grupos podem ser considerados como família, expressos no Estatuto da Família, e o projeto Escola Sem Partido, que coíbe o uso do conceito de gênero e expressões como identidade de gênero em sala de aula. Em junho de 2019, também houve a orientação do Itamaraty aos diplomatas brasileiros para que a utilização da palavra gênero somente acontecesse significando sexo biológico. Além disso, o Brasil se absteve na votação de uma resolução da ONU voltada para a garantia de direitos sexuais e reprodutivos (KREUZ, 2019).

Cabe ressaltar que o pensamento clássico conservador nasce na sociedade capitalista inicialmente como um olhar voltado para o passado, desejando a volta da sociedade feudal. O termo "conservador" foi usado pela primeira vez pelo Visconde de Chateaubriand (1768-1848) para denominar o periódico que publicava, a fim de difundir as ideias de restauração clerical e política. Ou seja, naquele período, o termo significava uma reação à Revolução Francesa e à queda do Antigo Regime.

Com o tempo, o termo passou a ser amplamente usado na Alemanha a partir de 1830 e foi oficialmente adotado na Inglaterra em 1835 (NISBET, 1981). Assinalamos que foi também a partir de 1830-1848 que o pensamento e a razão burguesa entraram em seu período de decadência ideológica, conforme denunciado por Marx e analisado por Lukács (NETTO, 1981). Ou seja, o pensamento burguês, que antes desse período se preocupava em desvelar a realidade e conhecê-la verdadeiramente, passa, a partir de então, a desempenhar uma função apologética e justificadora da sociabilidade burguesa.

Dessa maneira, nesse momento inicial o pensamento conservador desejava a volta da hierarquia, estabilidade e privilégios feudais e, por isso, tal forma de pensar encontrou enorme simpatia junto aos membros do clero católico, que se posicionou firmemente contrário aos ideais do lluminismo 


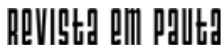

\} FAMÍLIA, CONSERVADORISMO E POLÍTICAS SOCIAIS NO BRASIL - SOUZA, I. L.; LIMA, R. L. \}

DOI: $10.12957 /$ REP.2019.45219

e da modernidade: a laicização do Estado, o racionalismo, o poder civil, o naturalismo, o humanismo, o liberalismo, a igualdade dos cultos perante a lei, o individualismo, o secularismo, o igualitarismo e o desrespeito às autoridades e hierarquias tradicionais (NISBET, 1981).

Nesse sentido, podemos assinalar como principais traços do pensamento conservador clássico: a) somente são legítimas as autoridades fundadas na tradição; b) a liberdade deve ser sempre uma liberdade restrita; c) a democracia é perigosa e destrutiva; d) a laicização é deletéria; e) a razão é destrutiva e inepta para organizar a vida social; f) a desigualdade é necessária e natural (ESCORSIM NETTO, 2011).

O pensamento conservador, com a consolidação do capitalismo, vai modificando sua função sociopolítica. De profundo crítico da nova ordem, se torna defensor da mesma, mantendo presente, contudo, a maioria dos traços elencados anteriormente. O "único deles que, no pós-48, tenderá a perder sua importância é o componente clerical, cada vez menos visível" (ESCORSIM NETTO, 2011, p. 67 - grifos no original). ${ }^{13}$

Com a modificação sobre o pensamento conservador, hoje, o termo designa comumente "uma disposição ou tendência para preservar o que está estabelecido" (NISBET, 1981, p. 62), estando geralmente associado à defesa da ordem e do status quo. Nesse processo de readaptação/readequação/refuncionalização do pensamento conservador, nasce o pensamento conservador moderno:

Depois de 1848, o conservadorismo confrontado com a 'questão social' e o movimento socialista revolucionário de base operária, rendeu-se à irreversibilidade do desenvolvimento capitalista e assumiu uma perspectiva essencialmente contrarevolucionária, oferecendo alternativas reformistas para preservar a ordem estabelecida e, incorporando, em sua tendência predominante, a racionalidade instrumental-positivista, mobilizou-se para elaborar a representação teórico-metodológica da sociedade burguesa. (ESCORSIM NETTO, 2011, p. 69).

Desse modo, após 1848, podemos afirmar que o pensamento conservador deixa de ser clássico e se torna moderno, passando, nesse processo de mudança, a defender a manutenção e a estabilidade da sociedade capitalista. Nesse sentido, alguns elementos fundamentais ao pensamento conservador persistem. Entre eles, assinalamos os seguintes: a) a sociedade tem natureza orgânica e por isso não pode ser desmembrada em indivíduos, pois os indivíduos sempre serão parte de um determinado grupo social. ${ }^{14}$

\footnotetext{
${ }^{13}$ Ressaltamos que o pensamento conservador afastou-se da defesa da ordem clerical como poder que deve organizar a sociedade. Contudo, o pensamento conservador vai continuar a enfatizar que, mais que a razão, o sentimento, a emoção e o sagrado são fundamentais à vida humana em sociedade (ESCORSIM NETTO, 2011).

${ }_{14}$ Também uma parte do pensamento de esquerda, durante muito tempo, menosprezou a expressão da individualidade, e tal expressão era vista como individualismo burguês. Hoje, parte da esquerda já fez uma crítica a tal postura e defende a plena expressão das individualidades, sem, contudo, confundir "expressão da individualidade" com o individualismo egoísta burguês.
} 


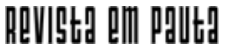

\} FAMÍLIA, CONSERVADORISMO E POLÍTICAS SOCIAIS NO BRASIL - SOUZA, I. L.; LIMA, R. L. \}

DOI: $10.12957 /$ REP.2019.45219

Entre tais grupos está a família, que deve ser sempre preservada, pois é base da sociedade, da moralidade e da estabilidade; b) os indivíduos têm necessidades inalteráveis, que são: a ordem, a religião, a tradição e a segurança; c) a vida moderna afastou os seres humanos dos valores ligados ao sagrado, desprezando a importância dos sentimentos e da emoção. A volta a um mundo onde haja mais sentimento, sagrado e moral é a solução para os problemas humanos; d) a estabilidade, a segurança e a ordem necessitam de autoridades e hierarquias. "Sem hierarquia na sociedade não pode haver estabilidade" (ESCORSIM NETTO, 2011, p. 70).

Tendo isso em vista, o pensamento conservador, ao longo da história, vai se metamorfoseando, mas sempre mantendo os pressupostos elencados acima. Na atualidade, o pensamento conservador, como já assinalamos, tem recrudescido a passos largos.

Os porta-vozes do capital na política e no mundo empresarial procuram lançar sobre a família o peso da responsabilidade pelas falhas e 'disfunções' cada vez mais frequentes, pregando de todos os púlpitos disponíveis a necessidade de 'retornar aos valores da familia tradicional' e aos 'valores básicos'. (MÉSZAROS, 2011, p. 272).

Retomando a relação entre Estado e família no Brasil, importa evidenciarmos que a denominada parceria entre essas duas esferas da vida social é invocada em um contexto de intensificação das desigualdades sociais e de significativas mudanças na estrutura do emprego e no trabalho, que é desqualificado. Além disso, há negação de direitos sociais mediante, por exemplo, sistemáticos cortes no orçamento federal ${ }^{15}$, com implicações diretas no desenvolvimento de políticas sociais. Torna-se, pois, estratégico para um Estado atrelado aos interesses do capital fortalecer a "solidariedade informal" e os apoios provenientes das redes primárias ou informais, nas quais estão inseridas as famílias, em detrimento do avanço de políticas sociais ancoradas em legítimas demandas e necessidades sociais, alicerçadas no conhecimento e na análise crítica da realidade que circunda o universo familiar na diversidade que the é inerente.

Nesse sentido, é pertinente resgatarmos a análise de Alencar (2004) sobre o fato de a família, no Brasil, talvez se configurar quase como a única possibilidade para os indivíduos quanto à provisão de suas necessidades. Principalmente "diante da inoperância ou ausência de mecanismos de proteção que levem em consideração os efeitos sociais recentes dos problemas originados da precarização do trabalho" (ALENCAR, 2004, p. 63). Contudo, a autora alerta acerca da necessidade de também considerarmos

\footnotetext{
${ }^{15}$ Em 2017, o Instituto de Estudos Socioeconômicos, junto com a Oxfam Brasil e o Centro para os Direitos Econômicos e Sociais, divulgou redução de até 83\% em políticas públicas para a área social desde 2014. Em 2018, a portaria 75 do Ministério do Planejamento publicou corte de ao menos $\mathrm{R} \$ 208,9 \mathrm{mi}$ de programas de combate à violência contra a mulher, do Incra, do SUS e de geração de emprego. Cf. Macedo (2017) e Scorce (2018).
} 


\section{ReVIStg a d P p putt}

\} FAMÍLIA, CONSERVADORISMO E POLÍTICAS SOCIAIS NO BRASIL - SOUZA, I. L.; LIMA, R. L. \}

DOI: $10.12957 /$ REP.2019.45219

que no quadro de crise econômica e da evidente retração do Estado na esfera social, ressurgem os discursos e as práticas de revalorização da família que, fundamentados numa concepção ideológica de cunho conservador, promovem e disseminam a proposição de que a família é a grande responsável por prover as necessidades dos indivíduos. (ALENCAR, 2004, p. 63).

Na perspectiva de políticas sociais apoiadas em um Estado familista, é pertinente demarcarmos situações atreladas à concepção de família que apontam para a continuidade de apreensões restritas e conservadoras inerentes a essa instituição social. Destacamos aqui o fato de, no chamamento das famílias por parte do Estado, ser sempre a mulher, no caso, a mulher-mãe, a que geralmente é solicitada a assumir tal tarefa. É esta, por exemplo, que deve estar atenta ao cumprimento de condicionalidades vinculadas aos programas sociais, de modo que as famílias permaneçam acessando-os. Estabelece-se a expectativa de a mulher cumprir, no âmbito familiar, a responsabilidade de cuidar - dos filhos, dos idosos, dos doentes e de todos os que necessitem de cuidados.

Nessa perspectiva, e conforme observa Campos (2015, p. 31), "[...]. Reforça-se a desigualdade do tratamento de gênero interno à família, influenciando nela a própria vida no tocante à reprodução social". Ainda segundo a autora, há, concomitantemente, um estímulo "à hierarquização entre o casal por meio dessa estruturação" (CAMPOS, 2015, p. 31). As muIheres permanecem sendo sobrecarregadas nas esferas privada e pública pelo fato de serem mulheres e com base em concepções e relações que ainda se aproximam da lógica que estrutura o patriarcado. Este, segundo o Dicionário crítico do feminismo, "vem da combinação das palavras gregas pater (pai) e arke (origem e comando)" (DELPHY, 2009, p. 174), designando uma formação na qual os homens detêm o poder. Conforme Saffioti (2004), o patriarcado é um sistema bem engendrado que oprime e explora as muIheres, sendo incorporado em suas vidas pelas próprias mulheres e que não requer, necessariamente, a presença do homem para fazê-lo funcionar.

Todavia, na perspectiva de um Estado familista, que convoca as famílias - na verdade, as mulheres - para assumirem responsabilidades ampliadas na proteção e no bem-estar social de seus membros, é visível a ausência do Estado na disponibilização de equipamentos e serviços públicos (creches, escolas em tempo integral, serviços de saúde, moradia digna, dentre outros) que garantam às famílias assumirem essa dimensão protetiva no nível nos parâmetros exigidos pelo Estado por meio de políticas sociais. A busca por tais serviços na esfera do mercado é impensável para as mulheres da classe trabalhadora mais empobrecida.

Para tais mulheres, a situação envolvendo as dificuldades em conciliar o desempenho que lhes é exigido nos espaços público e privado (pelo Estado, igrejas e pelas próprias famílias) se complexifica quando a renda recebida por elas é complemento essencial ao orçamento doméstico ou se 


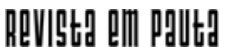

\} FAMÍLIA, CONSERVADORISMO E POLÍTICAS SOCIAIS NO BRASIL - SOUZA, I. L.; LIMA, R. L. \}

DOI: $10.12957 /$ REP.2019.45219

constitui como a única destinada à provisão familiar. Portanto, concordamos, em parte, com Carvalho (2015, p. 304) ao expor como um equívoco no âmbito das políticas públicas a escolha "apenas da mulher como porta de relação e parceria". Em nossa perspectiva, não se constitui um "equívoco", uma vez que se trata de um sistema de dominação-exploração que entrelaça capitalismo-racismo-heteropatriarcado como estrutura da sociedade contemporânea. Além disso, coloca sobre o ombro das mulheres mais empobrecidas - sobretudo, as mulheres negras - um conjunto de afazeres que deveria ser de responsabilidade pública.

Do desmonte das políticas sociais e da ausência do Estado, advém para as mulheres o aumento da carga de trabalho doméstico não remunerado [...]. Não havendo equipamentos como creches, hospitais, centros de convivência para idosos e crianças, lavanderias e restaurantes comunitários, serão as mulheres que absorverão tais tarefas (cuidar de crianças, idosos, doentes etc.). (BRASIL, 2004, p. 6).

Em concordância com Mioto e Dal Prá (2015, p. 172), compreendemos que, na relação Estado e família, no contexto da política social, a categoria cuidado vem assumindo centralidade, o que "tem levado a uma intensificação do trabalho familiar". Conforme levantamos neste artigo algumas notas a respeito, o ato de cuidar do outro permanece ainda sendo atribuído à mulher, quase sempre à mãe - mas, também, à avó, à filha, à tia, enfim, às mulheres presentes nas diversas famílias.

Para além das particularidades inerentes ao lugar que também o Estado atribui que a mulher assuma na esfera familiar (e para além desta), o fato é que a centralidade dada à família nas políticas sociais ainda não demonstra ampliada e crítica atenção aos processos de responsabilização das famílias que vêm sendo construídos. São repassadas para as famílias responsabilidades e obrigações envoltas na garantia de proteção e bem-estar de seus membros, as quais não necessariamente conseguem assumir.

Os membros da família não conseguem assumir tais "obrigações" em virtude de questões da própria ordem das relações familiares cotidianas, nem sempre pautadas no amor, na confiança e na proteção - como discursos conservadores teimam em ainda defender. "A idealização da família como lugar de aconchego e paz é outro mito que mascara a prática da violência em suas diversas formas: violência física, psicológica e sexual e maus-tratos contra mulheres, crianças, adolescentes e idosas/os". (PLATAFORMA FEMINISTA, 2002, p. 26).

Ao mesmo tempo, questões de ordem estrutural remetem ao capitalismo em seu estágio avançado no momento de reestruturação produtiva $^{16}$ - ocasionando desemprego, inserção em trabalhos precarizados e agravamento da situação de pobreza -, ao qual se mescla a formação

${ }^{16}$ Acerca do processo de reestruturação produtiva ver, entre outros, Antunes (2005). 


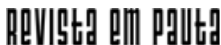

\} FAMÍLIA, CONSERVADORISMO E POLÍTICAS SOCIAIS NO BRASIL - SOUZA, I. L.; LIMA, R. L. \}

DOI: $10.12957 /$ REP.2019.45219

sócio-histórica brasileira: patriarcal, racista, patrimonialista, clientelista. Acarretam-se, assim, fortes rebatimentos nas famílias, sobrecarregando-as cada vez mais e, particularmente, as mulheres.

\section{Considerações finais ou em busca de valores emancipatórios}

Numa sociedade fundada na produção coletiva da riqueza e na apropriação privada dessa mesma riqueza, que é produzida pela maioria da humanidade, falar em adotar valores emancipatórios e coletivos - nos quais os seres humanos e a satisfação de suas necessidades sejam o elemento central, e não a produção da riqueza com vistas à sua acumulação - parece fora da realidade, principalmente quando estamos tratando da sociedade brasileira. Conforme assinalamos, esta é profundamente autoritária, verticalizada e patriarcal.

Todos nós, em maior ou menor medida, incorporamos os valores dominantes na sociedade. No nosso caso, são valores gestados na sociedade do capital, pois, como afirmam Marx e Engels (1991, p. 72), as "ideias da classe dominante são, em cada época, as ideias dominantes [...]". Nesse sentido, a cultura predominante imprime em nosso ser valores baseados no individualismo, competitividade e produtivismo. E, no caso da sociedade brasileira, somam-se a isso valores ligados ao patrimonialismo, autoritarismo, clientelismo, dentre outros.

Contudo, é preciso sempre considerar que saídas individuais e morais nunca transformaram nem transformarão o mundo. A moralidade vigente expressa relações sociais concretas, e é necessário transformar o conjunto das relações sociais para modificar a moralidade dominante. Nesse sentido, somente a práxis transforma o mundo, ou seja, não são as ideias que transformam o mundo - apesar de terem um papel importantíssimo e serem molas propulsoras para a ação no mundo. Enquanto molas propulsoras, as ideias e valores precisam desencadear ações no mundo - práxis coletivas, políticas e revolucionárias: "[...] Todas as formas e todos os produtos da consciência não podem ser dissolvidos por força da crítica espiritual, [...], só podem ser dissolvidos pela derrocada prática das relações reais [...]" (MARX; ENGELS, 1991, p. 56).

Isso não significa que devemos nos furtar de construir valores emancipatórios no nosso cotidiano, nos diversos espaços nos quais nos inserimos. Mas devemos ter claros os limites da construção de tais valores frente à cultura dominante, entendendo que tal cultura é cotidianamente produzida através da produção e reprodução do conjunto das relações sociais de produção capitalistas. Estabelecidos tais limites, passamos a perceber que nosso próprio pensamento se encontra limitado pelas condições objetivas postas pela sociabilidade presente. 


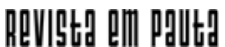

\} FAMÍLIA, CONSERVADORISMO E POLÍTICAS SOCIAIS NO BRASIL - SOUZA, I. L.; LIMA, R. L. \}

DOI: $10.12957 /$ REP.2019.45219

Por isso, é fundamental, mais do que nunca, a defesa intransigente de valores emancipatórios, somando-nos àqueles que defendem a construção de uma nova sociabilidade, na qual a liberdade não seja mera retórica e os seres humanos possam se desenvolver em plena liberdade, em todas as suas potencialidades e na sua rica diversidade.

Nesse sentido, é sempre necessário discutirmos e problematizarmos a noção de família e o familismo nas políticas sociais, desmistificando os limites intrínsecos de uma análise que a desconecta da genericidade humana e da construção de uma nova sociabilidade. 


\section{ReVIStg a d P p putt}

\} FAMÍLIA, CONSERVADORISMO E POLÍTICAS SOCIAIS NO BRASIL - SOUZA, I. L.; LIMA, R. L. \}

DOI: $10.12957 /$ REP.2019.45219

\section{Referências}

ALENCAR, M. M. T. Transformações econômicas e sociais no Brasil dos anos 1990 e seu impacto no âmbito da família. In: SALES, M. A.; MATOS, M. C. de; LEAL, M. C. (org.). Política social, família e juventude: uma questão de direitos. São Paulo: Cortez, 2004.

ANTUNES, R. Adeus ao trabalho? Ensaio sobre as metamorfoses e a centralidade do mundo do trabalho. São Paulo: Cortez, 2005.

BRASIL. Câmara dos Deputados. Relatório Final. Comissão Externa destinada a discutir a feminização da pobreza no Brasil. Brasília, DF, jun., 2004.

CAMPOS, M. S. O casamento da política social com a família: feliz ou infeliz. In: MIOTO, R. C. T.; CAMPOS, M. S.; CARLOTO, C. M. (Orgs.). Familismo, direitos e cidadania: contradições da política social. São Paulo: Cortez, 2015.

CARVALHO, M. do C. B. de. Famílias e políticas públicas. In: ACOSTA, A. R.; VITALE, M. A. F. (org.). Família: redes, laços e políticas públicas. São Paulo: Cortez, 2015.

CASTILHO, C. de F. V.; CARLOTO, C. M. O familismo na política de assistência social: um reforço à desigualdade de gênero? In: SIMPÓSIO SOBRE ESTUDOS DE GÊNERO E POLITICAS PÚBLICAS, 1. Anais [...]. Londrina: Universidade Estadual de Londrina, 2010.

CHAUÍ, M. Populismo: raízes teológicas do populismo no Brasil: teocracia dos dominantes, messianismo dos dominados. In: DAGNINO, E. (org.). Anos 90: política e sociedade no Brasil. São Paulo: Brasiliense, 1994.

CISNE, M.; SANTOS, S. M. M. dos. Feminismo, diversidade sexual e Serviço Social. São Paulo: Cortez, 2018.

DE MARTINO, M. Programas de transferência condicionadas, famílias e gênero: aproximações a alguns dilemas e desencontros. In: MIOTO, R. C. T.; CAMPOS, M. S.; CARLOTO, C. M. (org.). Familismo, direitos e cidadania: contradições da política social. São Paulo: Cortez, 2015.

DELPHY, C. Patriarcado. In: HIRATA, H. et al. (org.). Dicionário crítico do feminismo. São Paulo: Editora Unesp, 2009.

ENGELS, F. A origem da família da propriedade privada e do Estado. In: MARX, K.; ENGELS. Obras Escolhidas. V. 3. São Paulo: Alfa-Ômega, s.d.

ERGAS, Y. O feminismo dos anos 1960-1980. In: THÉBAUD, F.; DUBY, G.; PERROT, M. (ed.). História das mulheres no Ocidente. O século XX. Porto: Edições Afrontamento, 1991.

ESCORSIM NETTO, L. O conservadorismo clássico. Elementos de caracterização e crítica. São Paulo: Cortez, 2011. 


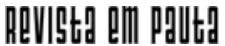

\} FAMÍLIA, CONSERVADORISMO E POLÍTICAS SOCIAIS NO BRASIL - SOUZA, I. L.; LIMA, R. L. \}

DOI: $10.12957 /$ REP.2019.45219

ESPING-ANDERSEN, G. Fundamentos sociales de las economias postindustriales. Barcelona: Ariel, 2011.

GELINSKI, C. R. O. G.; MOSER, L. Mudanças nas famílias brasileiras e a proteção desenhada. In: MIOTO, R. C. T.; CAMPOS, M. S.; CARLOTO, C. M. (org.). Familismo, direitos e cidadania: contradições da política social. São Paulo: Cortez, 2015.

KREUZ, L. Lawfare e igualdade de gênero: Itamaraty veda o uso do termo "gênero" para além do sexo biológico. 2019. Disponível em: http://www. justificando.com/2019/06/28/lawfare-e-igualdade-de-genero-itamaratyveda-o-uso-do-termo-genero-para-alem-do-sexo-biologico/. Acesso em: 28 jun. 2019.

MACEDO, Isabella. Estudo aponta queda de investimentos em áreas sociais e sugere revogação do teto de gastos. In: Congresso em Foco. Publicado em 16 de dezembro de 2017. Disponível em: <https://congressoemfoco .uol.com.br/especial/noticias/estudo-aponta-queda-de-investimentos-emareas-sociais-e-sugere-revogacao-do-teto-de-gastos/> Acesso em: $16 \mathrm{dez}$. 2017.

MARX, K.; ENGELS, F. Manifesto do Partido Comunista. In: MARX, K.; ENGELS. Obras Escolhidas. V. 1. São Paulo: Alfa-Ômega, s.d.

MARX, K.; ENGELS, F. A ideologia alemã (Feuerbach). São Paulo: Hucitec, 1991.

MÉSZÁROS, I. Para além do capital: rumo a uma teoria da transição. São Paulo: Boitempo, 2011.

MIOTO, R. C. T.; DAL PRÁ, K. R. Serviços sociais e responsabilização da família: contradições da política social. In: MIOTO, R. C. T.; CAMPOS, M. S.; CARLOTO, C. M. (Orgs.). Familismo, direitos e cidadania: contradições da política social. São Paulo: Cortez, 2015.

MIOTO, R. C. T. Novas propostas e velhos princípios: a assistência às famílias no contexto de programas de orientação e apoio sociofamiliar. In: SALES, M. A.; MATOS, M. C. de; LEAL, M. C. (org.). Política social, família e juventude: uma questão de direitos. São Paulo: Cortez, 2004.

NETTO, J. P. Lukács. Sociologia. São Paulo: Ática, 1981.

NISBET, R. A. Conservadorismo e sociologia. In: MARTINS, J. de S. (org.). Introdução crítica à sociologia rural. São Paulo: Hucitec, 1981.

OSTERNE, M. do S. F. Família, pobreza e gênero: o lugar da dominação masculina. Fortaleza: EDUECE, 2001.

PLATAFORMA FEMINISTA. In: Conferência Nacional de Mulheres Brasileiras. Brasília, 06 e 07 de junho de 2002. Disponível em: <http:// www.institutobuzios.org.br/documentos/PLATAFORMA\%20POLITICA \%20FEMINISTA.pdf>. Acesso em: 25 jun. 2018. 


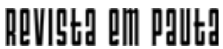

\} FAMÍLIA, CONSERVADORISMO E POLÍTICAS SOCIAIS NO BRASIL - SOUZA, I. L.; LIMA, R. L. \}

DOI: $10.12957 /$ REP.2019.45219

SAFFIOTI, H. Não há revolução sem teoria. In: SAFFIOTI, H. Gênero, patriarcado e violência. São Paulo: Fundação Perseu Abramo, 2004.

SCORCE, C. Governo Temer retira verba de area social para publicidade. Carta Capital [online]. Publicado em 25 de julho de 2018. Disponível em: $<$ https://www.cartacapital.com.br/economia/governo-temer-retira-verba-dearea-social-para-publicidade/> Acesso em: 22 de abr. de 2019

SIQUEIRA, L. Desenvolvimento e pobreza. Uma análise crítica. In: CONFERÊNCIA DO DESENVOLVIMENTO, 2, Brasília. Anais [...]. Brasília: Code/ Ipea, 2011.

DOI: $10.12957 /$ rep.2019.45219

Recebido em 30 de junho de 2018.

Aprovado para publicação em 14 de novembro de 2018.

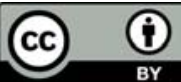

A Revista Em Pauta: Teoria Social e Realidade Contemporânea está licenciada com uma Licença Creative Commons Atribuição 4.0 Internacional. 